\title{
(C) OPEN ACCESS \\ Use of a maternal newborn audit and feedback system in Ontario: a collective case study
}

\author{
Jessica Reszel, ${ }^{\oplus, 2}$ Sandra I Dunn, ${ }^{1,2,3}$ Ann E Sprague, ${ }^{1,2,3}$ Ian D Graham, ${ }^{4,5}$ \\ Jeremy M Grimshaw, ${ }^{\odot, 5,6}$ Wendy E Peterson, ${ }^{3}$ Holly Ockenden, ${ }^{1}$ \\ Jodi Wilding, ${ }^{2}$ Ashley Quosdorf, ${ }^{3}$ Elizabeth K Darling, \\ Deshayne B Fell, ${ }^{2,5}$ JoAnn Harrold, ${ }^{2,4,8,9}$ Andrea Lanes, ${ }^{1,5}$ \\ Graeme N Smith, ${ }^{10}$ Monica Taljaard, ${ }^{4,5}$ Deborah Weiss, ${ }^{1,5}$ \\ Mark C Walker $1,4,5,11,12,13$
}

- Additional material is published online only. To view please visit the journal online (http://dx.doi.org/10.1136/ bmjas-2018-008354).

For numbered affiliations see end of article.

\section{Correspondence to} Jessica Reszel, BORN Ontario, Ottawa, ON K1H 8L1, Canada; jreszel@cheo.on.ca

Received 18 May 2018 Revised 11 January 2019 Accepted 20 January 2019 Published Online First 16 February 2019
Check for updates

(c) Author(s) (or their employer(s)) 2019. Re-use permitted under CC BY-NC. No commercial re-use. See rights and permissions. Published by BMJ.

To cite: Reszel J, Dunn SI, Sprague AE, et al.

BMJ Qual Saf

2019:28:635-644.

\begin{abstract}
Background As part of a larger study examining the effectiveness of the Maternal Newborn Dashboard, an electronic audit and feedback system to improve maternal-newborn care practices and outcomes, the purpose of this study was to increase our understanding of factors explaining variability in performance after implementation of the Dashboard in Ontario, Canada. Methods A collective case study. A maximum variation sampling approach was used to invite hospitals reflecting different criteria to participate in a 1-day to 2-day site visit by the research team. The visits included: (1) semistructured interviews and focus groups with healthcare providers, leaders and personnel involved in clinical change processes; (2) observations and document review. Interviews and focus groups were audio-recorded and transcribed verbatim. Qualitative content analysis was used to code and categorise the data.

Results Between June and November 2016, we visited 14 maternal-newborn hospitals. Hospitals were grouped into four quadrants based on their key indicator performance and level of engagement with the Dashboard. Findings revealed four overarching themes that contribute to the varying success of sites in achieving practice change on the Dashboard key performance indicators, namely, interdisciplinary collaboration and accountability, application of formal change strategies, team trust and use of evidence and data, as well as alignment with organisational priorities and support. Conclusion The diversity of facilitators and barriers across the 14 hospitals highlights the need to go beyond a 'one size fits all' approach when implementing audit and feedback systems. Future work to identify tools to assess barriers to practice change and to evaluate the effects of cointerventions to optimise audit and feedback systems for clinical practice change is needed.
\end{abstract}

\section{BACKGROUND}

In Canada and the USA, labour/birth is the top reason for admission to hospital ${ }^{12}$ and wide variation in clinical practices and outcomes is observed, ${ }^{34}$ suggesting that optimal care is not always delivered and room for improvement exists. The Better Outcomes Registry \& Network (BORN) is an internet-based data collection system operating since 2012 in all Ontario hospitals providing maternal-newborn care. Pregnancy, birth and childhood data are held in the BORN Information System, henceforth referred to as the registry, and is available to users to facilitate care. To increase awareness among Ontario maternal-newborn hospitals and care providers regarding performance and quality of care issues, BORN Ontario implemented the Maternal Newborn Dashboard (the Dashboard) within the registry in November 2012. ${ }^{5}$ The Dashboard is an electronic audit and feedback system that provides hospitals with near real-time feedback, peer comparison data and provincial benchmarks for practice change on six key performance indicators (KPIs). Following a rigorous process, the KPIs were selected for their clinical relevance, measurability using the available registry data and amenability to change. ${ }^{5}$ The associated benchmarks were established following review of the evidence, current clinical practice rates in Ontario and input from an interprofessional panel of clinical experts. ${ }^{5}$ The Dashboard home page (figure 1) provides hospital rates for each KPI, a colour signal aligned with the benchmarks and peer and provincial comparison rates. Additional data tables are also available for each KPI providing detailed information about the numerator and denominator, confidence intervals and missing data to facilitate interpretation. 


\begin{tabular}{|c|c|c|c|c|c|c|c|c|c|}
\hline \multirow{2}{*}{\multicolumn{2}{|c|}{ Key Performance Indicators }} & \multirow[b]{2}{*}{ Rate (\%) } & \multirow[b]{2}{*}{ Status } & \multicolumn{3}{|c|}{ Benchmark rates (\%) } & \multicolumn{3}{|c|}{ Comparator rates (\%) } \\
\hline & & & & $\begin{array}{l}\text { Target } \\
\text { (green) }\end{array}$ & $\begin{array}{l}\text { Warning } \\
\text { (yellow) }\end{array}$ & $\begin{array}{l}\text { Alert } \\
\text { (red) }\end{array}$ & $\begin{array}{c}\text { Other } \\
\text { Neonatal } \\
\text { Level IIIa/IIIlb } \\
\text { hospitals }\end{array}$ & $\begin{array}{l}\text { Other }>4000 \\
\text { birth volume } \\
\text { hospitals }\end{array}$ & Ontario \\
\hline 1 & $\begin{array}{l}\text { Proportion of newborn screening samples that } \\
\text { were unsatisfactory for testing }\end{array}$ & 2.6 & & $<1.0$ & 21.0 and $<1.5$ & 21.5 & 0.6 & 1.5 & 1.4 \\
\hline 2 & $\begin{array}{l}\text { Rate of episiotomy in women who had a } \\
\text { spontaneous vaginal birth }\end{array}$ & 13.5 & & $<13.0$ & $13.0-17.0$ & $>17.0$ & 5.9 & 9.3 & 8.2 \\
\hline 3 & $\begin{array}{l}\text { Rate of formula supplementation from birth to } \\
\text { discharge in term infants whose mothers } \\
\text { intended to exclusively breastfeed }\end{array}$ & 1.6 & & $<20.0$ & $20.0-25.0$ & $>25.0$ & 16.4 & 25.3 & 23.8 \\
\hline 4 & $\begin{array}{l}\text { Proportion of women with a cesarean section } \\
\text { performed from } 237 \text { to }<39 \text { weeks' gestation } \\
\text { among low-risk women having a repeat } \\
\text { cesarean section at term }\end{array}$ & 4.2 & & $<11.0$ & $11.0-15.0$ & $>15.0$ & 19.0 & 41.6 & 36.9 \\
\hline 5 & $\begin{array}{l}\text { Proportion of women who delivered at term } \\
\text { and had Group B Streptococcus (GBS) } \\
\text { screening at 35-37 weeks' gestation }\end{array}$ & 53.4 & & $>94.0$ & $90.0-94.0$ & $<90.0$ & 98.1 & 92.8 & 91.1 \\
\hline 6 & $\begin{array}{l}\text { Proportion of women who were induced with } \\
\text { an indication of post-dates and were less than } \\
41 \text { weeks' gestation at delivery }\end{array}$ & 67.1 & & $<5.0$ & $5.0-10.0$ & $>10.0$ & 9.5 & 6.6 & 17.3 \\
\hline
\end{tabular}

Data source BORN Ontario, 2016-2017

Figure 1 Sample Maternal Newborn Dashboard homepage.

A Cochrane review reported that the use of audit and feedback interventions is associated with a median $4.3 \%$ increase in desired practice (IQR 0.5\%-16\%). ${ }^{6}$ Our evaluation of the Dashboard demonstrated a statistically significant absolute improvement on four out of six KPIs, with the magnitude of effect ranging from 1.5 to 11.7 per hundred at 30 months postimplementation, ${ }^{7}$ which is consistent with the 2012 Cochrane review. ${ }^{6}$ Although the Dashboard triggered improvements in care, the observed effects were variable across hospital sites and the six KPIs. The effectiveness of audit and feedback may be influenced by a variety of factors, including the nature of the clinical behaviour change, the baseline performance and the source, format and frequency of the feedback. ${ }^{6}$ Key characteristics of the Dashboard that align with recommendations to optimise the effectiveness of audit and feedback include use of timely data (ie, near real-time), ongoing and continuous feedback (ie, rather than one-off), relevant comparators (ie, by similar level of care and birth volume) and from a credible source (ie, the province's birth registry). ${ }^{8}$

Yet even with an optimally designed intervention, it is important to consider the context in which the change is being implemented. Existing literature and knowledge translation frameworks have identified common factors influencing uptake of evidence into practice, including the attributes of the innovation and the adopters and structural and social factors within the practice environment; ${ }^{9-12}$ barriers to behaviour change $;^{13}$ implementation strategies ${ }^{1014} 15$ and the organisational receptiveness/readiness for change. ${ }^{10} 16$ In addition, a recent systematic review of qualitative studies evaluating characteristics of healthcare organisations struggling to improve quality of care identified key influencing domains including poor organisational culture, inadequate infrastructure, lack of a cohesive mission, system shocks and dysfunctional external relations. ${ }^{17}$ As such, it is important to increase our understanding of specific factors influencing hospital use of the Dashboard to develop targeted strategies to support sites to improve maternal-newborn care and outcomes. Thus, the purpose of this study was to identify factors that facilitate and impede hospitals' use of the Dashboard to improve clinical practice and outcomes on the KPIs.

\section{METHODS}

\section{Study design}

As part of a larger sequential mixed-methods study to evaluate the effect of the Dashboard on six KPIs, ${ }^{18}$ we completed a collective case study ${ }^{19}$ using a qualitative descriptive approach ${ }^{20} 21$ to facilitate comparison between diverse settings. Specifically, we aimed to understand how maternal-newborn hospitals used the Dashboard for clinical practice change and why some hospitals were successful and others were not.

\section{Setting}

The setting was Ontario, Canada. We defined a 'case' as an Ontario hospital providing maternal-newborn care, allowing for inclusion of both the maternal-newborn 
unit and the broader hospital system in which it is embedded. ${ }^{19}$ In Canada, healthcare is a publicly funded single-payer system. In Ontario specifically, there are approximately 140000 births per year, $97 \%$ of which occur in hospital. ${ }^{22}$ Nearly $80 \%$ of hospital births are attended by obstetricians, $8 \%$ by family physicians and $10 \%$ by midwives. $^{3}$

\section{Sampling}

We used a maximum variation sampling approach ${ }^{23}$ to identify hospitals reflecting different criteria (newborn level of care, birth volumes, geographic locations, KPI performance following implementation of the Dashboard).

\section{Recruitment}

Invitations were sent to the obstetrical manager/ director of selected hospitals over 5 months, allowing us to examine characteristics of accepting hospitals and target specific hospitals to ensure maximum variation in sampling. Recruitment ended when sampling saturation was achieved (ie, hospitals reflecting the different criteria were recruited). Managers/directors of recruited sites were asked to identify and invite healthcare providers, hospital leaders and other personnel involved in the clinical change process to participate in the site visit. Additionally, the research team invited each hospital's BORN Coordinator, who helps facilitate data entry into the registry, to provide feedback about their hospitals' use of the Dashboard data during follow-up individual telephone interviews.

\section{Data collection}

We conducted 1-day to 2-day hospital site visits comprised of interviews/focus groups (online supplementary table 1), observations and document review. If participants were unable to attend an interview/ focus group in person, an individual interview was conducted by telephone $(n=7)$. Interviews and focus groups were conducted by research team members trained in qualitative data collection and who were unknown to participants. All participants signed a written consent form prior to participation. On average, focus groups, dyadic interviews (ie, with two participants), ${ }^{24}$ and individual interviews lasted $58 \mathrm{~min}, 48 \mathrm{~min}$ and $36 \mathrm{~min}$, respectively. Interviews and focus groups were audio-recorded and transcribed verbatim. One interview participant declined to be audio-recorded so notes were taken.

Managers/directors were asked to provide opportunities to observe the day-to-day activities of the maternal-newborn units and/or hospital, including unit tours and attendance at departmental meetings. Detailed notes of observations and photographs augmented the data. Last, managers/directors were asked to share relevant documents with the research team, including policies/procedures, educational materials and patient resources.

\section{Data analysis}

All transcripts were uploaded to NVivo11. ${ }^{25}$ We used conventional content analysis to code and categorise the data. ${ }^{26}$ Four research team members coded the data, with $40 \%$ of transcripts coded independently by two team members to increase trustworthiness. ${ }^{27}$ The following process was used: (1) transcript was read as a whole; (2) transcript was re-read and coded; (3) team members met after every two to three transcripts to compare coding and develop and revise the coding scheme. The codes were subsequently grouped into broader themes, which were discussed by the research team at regular meetings. After analysing the data sources for each hospital, an interpretive summary was written for the case according to predefined questions (online supplementary table 2).

Next, based on emergent themes from our data, we grouped cases into four quadrants according to KPI performance (high performance $\left(\mathrm{P}^{+}\right) /$low performance $\left.\left(\mathrm{P}^{*}\right)\right)$ and level of engagement with the Dashboard (high engagement $\left(E^{+}\right) /$low engagement $\left.\left(E^{-}\right)\right)$(table 1) to facilitate identification of similarities and differences among hospitals within and between quadrants.

\section{RESULTS}

We invited 31 out of 94 potential hospitals to participate in a site visit, and between June and November 2016, we visited 14 Ontario maternal-newborn hospitals (table 2), located within 9 of 14 health regions in the province. A total of 107 people participated in an interview or focus group (online supplementary table 3 ).

Our findings revealed four overarching themes that contribute to the varying success of sites on the Dashboard KPIs, namely, interdisciplinary collaboration and accountability, application of formal change strategies, team trust and use of evidence and data, as well as alignment with organisational priorities and support (table 3 ). We present a description of these overarching themes to illustrate how these factors facilitated and impeded use of the Dashboard for clinical practice change. Illustrative quotes are presented in table 4.

\section{Interdisciplinary collaboration and accountability}

High performing sites $\left(\mathrm{Q} 1: \mathrm{P}^{+} / \mathrm{E}^{+}, \quad \mathrm{Q} 2: \mathrm{P}^{+} / \mathrm{E}^{-}\right)$ described positive relationships between different professions such as nursing and physicians, often with a flattened hierarchy. For example, a strategy used by some sites to improve specific KPIs (such as KPI 4: caesarean sections, KPI 6: inductions) (figure 1) was to empower members of the healthcare team to communicate interprofessionally and collectively own the identified practice issue. While some sites with low performance $\left(\mathrm{Q} 3: \mathrm{P}^{-} / \mathrm{E}^{+}, \mathrm{Q} 4: \mathrm{P}^{-} / \mathrm{E}^{-}\right)$stated that physician caesarean section and induction bookings were not within the control of nurses, multiple high performing sites described 'empowering' nurses 
Table 1 Definitions of performance and engagement used to classify hospital sites into four quadrants

\begin{tabular}{|c|c|c|c|}
\hline Variable & Definitions & Data sources used & Site classification process \\
\hline $\begin{array}{l}\text { Performance } \\
\text { ie, how successful was the hospital } \\
\text { in achieving 'green' on the } 6 \\
\text { Dashboard KPIs? }\end{array}$ & $\begin{array}{l}\text { High performance on KPIs }\left(\mathrm{P}^{+}\right) \text {: } \\
\text { *Of the KPIs that could be improved (red/ } \\
\text { yellow), }>50 \% \text { of KPIs improved to green between } 1 \\
\text { April } 2013 \text { and } 31 \text { March } 2016 \text { and } \\
\text { Green on } \geq 4 \mathrm{KPIs} \text { as of } 31 \text { March } 2016 \\
\text { Low performance on KPIs }\left(\mathrm{P}^{-}\right) \text {: } \\
\text { Of the KPIs that could be improved (red/yellow), } \leq 50 \% \\
\text { of KPIs improved to green between } 1 \text { April } 2013 \text { and } \\
31 \text { March } 2016 \text { and } \\
\text { Green on } \leq 3 \mathrm{KPIs} \text { as of } 31 \text { March } 2016\end{array}$ & Provincial registry data & $\begin{array}{l}\text { Two analysts independently } \\
\text { classified each of the } 14 \text { sites as } \\
\text { 'high' or 'low' performance. } \\
\text { Consensus was reached for all } 14 \\
\text { sites. }\end{array}$ \\
\hline $\begin{array}{l}\text { Engagement } \\
\text { ie, overall, how engaged was the } \\
\text { hospital in using the Dashboard to } \\
\text { facilitate clinical practice change on } \\
\text { the KPIs? }\end{array}$ & $\begin{array}{l}\text { High engagement with Dashboard }\left(\mathrm{E}^{+}\right) \text {: } \\
\text { Provided examples of use of the Dashboard and } \\
\text { targeted efforts to facilitate clinical practice change } \\
\text { on the KPIs } \\
\text { Low engagement with Dashboard }\left(\mathrm{E}^{-}\right) \text {: } \\
\\
\text { Provided limited examples of use of the Dashboard and } \\
\text { targeted efforts to facilitate clinical practice change } \\
\text { on the KPIs }\end{array}$ & $\begin{array}{l}\text { Interviews } \\
\text { Focus groups } \\
\text { Hospital documents } \\
\text { Observations } \\
\text { Photographs } \\
\text { Field notes } \\
\text { Interpretive summaries }\end{array}$ & $\begin{array}{l}\text { Two analysts independently } \\
\text { classified each of the } 14 \text { sites as } \\
\text { 'high' or 'low' engagement. } \\
\text { Consensus was reached for all } 14 \\
\text { sites. }\end{array}$ \\
\hline
\end{tabular}

*With the exception of one site who was already green on six KPIs in April 2013. This site was recruited to provide the team with a case who had been successful with sustaining a high level of performance on the KPIs over a 3-year period.

$\mathrm{E}$, engagement with Dashboard; KPI, key performance indicator; P, performance on KPIs.

to talk to physicians about their practices as an important strategy to ensure alignment with current Dashboard recommendations.

Sites with low performance $\left(\mathrm{Q} 3: \mathrm{P}^{-} / \mathrm{E}^{+}, \mathrm{Q} 4: \mathrm{P}^{-} / \mathrm{E}^{-}\right)$ described challenges in interprofessional relationships at their sites and a lack of interprofessional representation on committees. Several sites expressed a lack of collective accountability for practice issues. For example, nurses would state that they did not have any influence on physician practices (related to KPIs $2,4,5,6)$ (figure 1) and some physicians stated they did not have any influence on their peers' practices. This individualised approach was congruent with the 'divide' described between the different professional groups, which likely limited success on improving performance.

\begin{tabular}{|c|c|c|c|c|}
\hline & $\begin{array}{l}\text { Quadrant } 1 \\
\mathrm{P}^{+} / \mathrm{E}^{+*} \\
\mathrm{~N}=7\end{array}$ & $\begin{array}{l}\text { Quadrant } 2 \\
\mathrm{P}^{+} / \mathrm{E}^{-} \dagger \\
\mathrm{N}=2\end{array}$ & $\begin{array}{l}\text { Quadrant } 3 \\
\mathrm{P}^{-} / \mathrm{E}^{+} \ddagger \\
\mathrm{N}=3\end{array}$ & $\begin{array}{l}\text { Quadrant } 4 \\
\mathrm{P}^{-} / \mathrm{E}^{-} \S \\
\mathrm{N}=2\end{array}$ \\
\hline \multicolumn{5}{|l|}{ Level of care-n (\%)ף } \\
\hline Low-risk & $2(29)$ & $2(100)$ & $0(0)$ & $0(0)$ \\
\hline High-risk & $5(71)$ & $0(0)$ & $3(100)$ & $2(100)$ \\
\hline \multicolumn{5}{|l|}{ Birth volume/year-n (\%) } \\
\hline$\leq 500$ & $2(29)$ & $2(100)$ & $0(0)$ & $0(0)$ \\
\hline $501-2499$ & $3(43)$ & $0(0)$ & $1(33)$ & $1(50)$ \\
\hline$\geq 2500$ & $2(29)$ & $0(0)$ & $2(67)$ & $1(50)$ \\
\hline \multicolumn{5}{|l|}{ Method of data entry into provincial registry—n (\%) } \\
\hline Manual & $5(71)$ & $1(50)$ & $2(67)$ & $1(50)$ \\
\hline Upload from EHR & $2(29)$ & $1(50)$ & $1(33)$ & $1(50)$ \\
\hline $\begin{array}{l}\text { Of the KPIs that were red/yellow in April 2013, percent that changed } \\
\text { to green by March 2016-mean (SD) } \\
\text { (range) }\end{array}$ & $\begin{array}{l}72(36.7) \\
(0-100)^{* *}\end{array}$ & $\begin{array}{l}63(4.7) \\
(60-67)\end{array}$ & $\begin{array}{l}26(6.6) \\
(20-33)\end{array}$ & $0(0)$ \\
\hline $\begin{array}{l}\text { Number of KPIs green in March } 2016 \text { (out of 6)—mean (SD) } \\
\text { (range) }\end{array}$ & $\begin{array}{l}5(0.8) \\
(4-6)\end{array}$ & $\begin{array}{l}4.5(0.7) \\
(4-5)\end{array}$ & $\begin{array}{l}2.3(0.6) \\
(2-3)\end{array}$ & $\begin{array}{l}2(1.4) \\
(1-3)\end{array}$ \\
\hline
\end{tabular}

*Quadrant 1: High performance, high engagement.

tQuadrant 2: High performance, low engagement.

‡Quadrant 3: Low performance, high engagement.

$\S$ Quadrant 4: Low performance, low engagement.

ILow-risk includes level I hospitals; high-risk includes level II and III hospitals; level of care defined as per the Provincial Council for Maternal and Child Health. 37

${ }^{* *}$ Including one site who was green on all six KPIs at baseline.

E, engagement with Dashboard; EHR, electronic health record; KPI, key performance indicator; P, performance on KPIs. 
Table 3 Themes by quadrant

\begin{tabular}{|c|c|c|c|c|}
\hline & $\begin{array}{l}\text { Quadrant } 1 \\
\left(\mathrm{P}^{+} / \mathrm{E}^{+}\right)\end{array}$ & $\begin{array}{l}\text { Quadrant } 2 \\
\left(\mathrm{P}^{+} / \mathrm{E}^{-}\right)\end{array}$ & $\begin{array}{l}\text { Quadrant } 3 \\
\left(\mathrm{P}^{-} / \mathrm{E}^{+}\right)\end{array}$ & $\begin{array}{l}\text { Quadrant } 4 \\
\left(\mathrm{P}^{-} / \mathrm{E}^{-}\right)\end{array}$ \\
\hline Interdisciplinary collaboration and accountability & $\checkmark$ & $\checkmark$ & $x$ & $x$ \\
\hline Application of formal change strategies & $\checkmark$ & $x$ & $\checkmark$ & $x$ \\
\hline Team trust and use of evidence and data & $\checkmark$ & $\checkmark$ & $x$ & $x$ \\
\hline Alignment with organisational priorities and support & $\checkmark$ & $x$ & $\checkmark$ & $x$ \\
\hline
\end{tabular}

$\checkmark$ Overall, these factors were present at organisations within this quadrant and were perceived to facilitate Dashboard KPI improvements.

${ }^{x}$ Overall, these factors were lacking at organisations within this quadrant and were perceived to be barriers to Dashboard KPI improvements.

$\mathrm{E}$, engagement with Dashboard; KPI, key performance indicator; P, performance on KPIs.

\section{Application of formal change strategies}

High engagement sites $\left(\mathrm{Q} 1: \mathrm{P}^{+} / \mathrm{E}^{+}, \mathrm{Q} 3: \mathrm{P}^{/} / \mathrm{E}^{+}\right)$gave extensive examples of strategies used to improve on KPIs. Examples included auditing specific cases contributing to red/yellow signals on the Dashboard and following up with staff, developing new policies, procedures and documentation forms as well as implementing individual-level and group-level staff-targeted education. Despite the use of a variety of strategies to improve clinical practice, a key difference between $\mathrm{Q} 1\left(\mathrm{P}^{+} / \mathrm{E}^{+}\right)$and $\mathrm{Q} 3$ $\left(\mathrm{P} / \mathrm{E}^{+}\right)$that may have influenced performance was the consistent application of various change frameworks by Q1, which facilitated leaders' ability to be with the frontline workers, identify problems and empower and coach staff to develop and implement solutions to problems. In contrast, despite the presence of a highly engaged leader, only one of the three sites in $\mathrm{Q} 3\left(\mathrm{P} / \mathrm{E}^{+}\right)$identified a formal framework used for change, resulting in a less coordinated approach to clinical practice change with inconsistent involvement in the change process from the broader team.

Table 4 Participant quotes by theme to illustrate barriers and facilitators

\section{Facilitators \\ Barriers}

Interdisciplinary collaboration and We did collaborate with our obstetric group to say these are our It's hard to quantify whose numbers they are, who accountability standards and these are our clinical indications for inductions... the patient belongs to. So you have patients that So it's become a very good collaboration between nursing staff, you see in your office and you make plans for their team leaders, triage nurses, as well as myself (manager). The labour and delivery or C-section, etc. and those are long-term plan for this is to move it away from myself and move your patients from the office. But then when you're it to the team leaders and then to the triage nurses so that it has a sustainable approach to it moving forward. $\left(\mathrm{Q} 1: \mathrm{P}^{+} / \mathrm{E}^{+}\right.$, Site N) on call, you react to what comes in the door. And so it's a bit tricky to own any stats because you're being given the information based on how you perform when you're on call. (Q3:P// $\mathrm{E}^{+}$, Site $\left.\mathrm{M}\right)$

Application of formal change strategies

This is the first organization I'd been in who has really engaged in [name of change framework] from boardroom to bedside and that's extremely important. The concept of [name of change framework] is a philosophy. It's a performance management methodology that really transforms your culture. $\left(\mathrm{Q} 1: \mathrm{P}^{+} / \mathrm{E}^{+}\right.$, Site B)

Team trust and use of evidence
and data
Alignment with organisational
priorities and support

If you start at the beginning, they trust the process on how they get the data in, right?... They understand that the nurse looking after the patient is the right person to enter the data accurately... They trust the (registry) data quality reports that they use... and they trust the Dashboard in that there is a mechanism in the Dashboard to drill down into it. They're able to do a little audit and through that process, make changes if need be but also when everything comes up and it's all been entered accurately by chart audit, they trust the Dashboard. So all of those things have built up a trust and it didn't come overnight, right? $\left(\mathrm{Q} 1: \mathrm{P}^{+} / \mathrm{E}^{+}\right.$, Site $\left.\mathrm{D}\right)$

Our induction strategy became a priority for two reasons. Number one, because we were performing poorly on the metric (KPI 6), but number two, it was significantly affecting our patient flow and our clinical flow because our inductions were very much unregulated. Some days we would have nine, other days we'd have zero, which is very hard because of staffing issues that we were facing at the time. So it (KPI 6) became a programme priority. (Q1: $\mathrm{P}^{+} / \mathrm{E}^{+}$, Site $\left.\mathrm{N}\right)$ 
Sites classified in $\mathrm{Q} 2\left(\mathrm{P}^{+} / \mathrm{E}^{-}\right)$also did not describe a concrete process or framework for clinical practice change, with one site perceiving that change happened 'randomly'. Yet despite this lack of formal change process, the $\mathrm{Q} 2\left(\mathrm{P}^{+} / \mathrm{E}^{-}\right)$sites showed more improvement on the KPIs compared with some other sites visited, which is likely attributable to the structural characteristics of the hospital sites (eg, small teams with fewer decision makers and less 'red tape'). In Q4 $\left(\mathrm{P}^{-} / \mathrm{E}^{-}\right)$, there were limited examples of formal change processes initiated to target Dashboard KPIs, which likely contributed to the lack of improvement.

\section{Team trust and use of evidence and data}

High performance sites $\left(\mathrm{Q} 1: \mathrm{P}^{+} / \mathrm{E}^{+}, \quad \mathrm{Q} 2: \mathrm{P}^{+} / \mathrm{E}^{-}\right)$ described specific systems for entering, auditing and sharing Dashboard data. Among Q1 $\left(\mathrm{P}^{+} / \mathrm{E}^{+}\right)$specifically, all sites took ownership for their data quality, invested significant time to ensure that the Dashboard output was accurate and trustworthy and dedicated resources to resolving data quality issues through regular audits and staff training. These systems for improving data quality enhanced trust in the Dashboard and facilitated planning, implementing and monitoring clinical practice changes. In addition, these sites described how Dashboard data were shared systematically throughout their organisation and at regional network meetings (eg, departmental meetings, huddles, hospital display boards, email). These sites valued sharing the Dashboard data to reinforce positive practice changes, showcase successes, highlight areas for improvement related to data quality and practice changes and facilitate priority-setting. A unique finding related to data in $\mathrm{Q} 2\left(\mathrm{P}^{+} / \mathrm{E}^{-}\right)$sites was that some of the improved performance on their KPIs was related to improved data entry rather than changes in clinical practice.

Conversely, in low performance sites $\left(\mathrm{Q} 3: \mathrm{P}^{-} / \mathrm{E}^{+}, \mathrm{Q} 4: \mathrm{P}\right.$ $\left./ \mathrm{E}^{-}\right)$, there were challenges related to the team's beliefs in the evidence backing the selected KPIs and associated benchmarks and challenges related to understanding and using data. These sites questioned the evidence behind the KPI benchmarks and some gave examples of how change was limited by physicians' belief that there would be no negative clinical impact for their patients if they did not adhere to the gestational age cut-off set for the KPI benchmarks (ie, KPI 4: caesarean section; KPI 6: inductions) (figure 1). In addition, in $\mathrm{Q} 3\left(\mathrm{P}^{-} / \mathrm{E}^{+}\right)$participants demonstrated an implicit or explicit lack of knowledge regarding the intricacies of the KPIs, such as the precise definitions for the KPI numerators and denominators. Without a full understanding of such intricacies, efforts to target KPIs did not always translate into improvements on the Dashboard. In Q4 $\left(\mathrm{P}^{-} / \mathrm{E}^{-}\right)$, there were significant concerns about the accuracy of the data and the Dashboard output, resulting in limited action to improve the clinical practice issues related to the KPIs. Mistrust in the accuracy of the Dashboard output led to a continual need to 'prove' there was a clinical problem before team members would consider planning and implementing quality improvement initiatives.

Of the nine sites that entered data manually, seven were classified as highly engaged. Although some of these sites discussed the time-consuming nature of manual data entry and the desire to transition to uploading data from the patient electronic record into the registry, these sites described more frequent access to and awareness of the data in the registry. For some sites, manual data entry facilitated trust in the data and the output of the Dashboard. This was especially true when team collaboration was high, and the team trusted that the people who entered the data into the registry to populate the Dashboard have done so carefully and accurately.

\section{Alignment with organisational priorities and support}

The alignment between the Dashboard and current organisational priorities and the availability of sufficient resources to implement changes influenced the extent to which sites engaged with the Dashboard system and were able to improve performance. All high engagement sites $\left(\mathrm{Q} 1: \mathrm{P}^{+} / \mathrm{E}^{+}, \mathrm{Q} 3: \mathrm{P}^{-} / \mathrm{E}^{+}\right)$identified how one or more of the KPIs aligned with their existing regional, institutional (eg, strategic plan or Baby Friendly Initiative accreditation) or unit priorities. This increased integration of the Dashboard and the focus on specific KPIs into current work. In addition, all sites in $\mathrm{Q} 1\left(\mathrm{P}^{+} / \mathrm{E}^{+}\right)$identified key roles and individuals within their organisations that facilitated use of the Dashboard, including directors, managers, clinical educators as well as internal BORN data champions. Regardless of the specific job title, these individuals were viewed as having dedicated time, resources, skills and passion to support the team to fully use the Dashboard and facilitate clinical practice changes.

Both sites in $\mathrm{Q} 2\left(\mathrm{P}^{+} / \mathrm{E}^{-}\right)$were small and experienced challenges with resources, especially with KPI 4 (caesarean sections) (figure 1). Specifically, both relied on their hospital's main operating room and were limited to specific dates and times to conduct caesarean sections. This led to some obstetricians conducting caesarean sections prior to the recommended 39 weeks' gestation. Neither site met the KPI 4 benchmark, largely due to resource limitations.

In $\mathrm{Q} 4\left(\mathrm{P}^{-} / \mathrm{E}^{-}\right)$, there was a lack of alignment between their hospital or unit priorities and the Dashboard. For instance, one site described how their hospital had prioritised growth of other clinical areas, with fewer resources for the maternal-newborn programme. Another site described investment in other maternal-newborn initiatives, leaving less capacity to target the Dashboard KPIs.

\section{DISCUSSION}

Findings from our study revealed diverse hospital responses to and experiences with the Dashboard audit 
and feedback system. We identified key themes related to interdisciplinary collaboration and accountability, the application of formal change strategies, team trust and use of evidence and data, as well as alignment with organisational priorities and support. These factors influenced how engaged teams were with the Dashboard system and their performance on the six KPIs.

Our study identified barriers and facilitators to clinical practice change related specifically to the quality and use of data. In all four quadrants, we identified either facilitators or barriers to KPI improvement related to the existence of reliable data entry systems, team trust of the data entry processes and the Dashboard output, sharing of data among the team and organisation and level of understanding of the KPI definitions (ie, numerator and denominator definitions) which influenced how the data were interpreted. For audit and feedback to be effective, the information must be perceived as credible. ${ }^{8}$ Trust in the quality of the data was the most commonly identified influencing factor reported in a systematic review of use of medical registries giving information feedback to healthcare providers. $^{28}$ This same barrier to change was also identified by members of our team in an earlier pilot of KPI 4 (caesarean sections) (figure 1), with some team members doubting the credibility of the hospital-level data. ${ }^{29}$ With the Dashboard, each hospital is responsible for the data that is entered in the registry and subsequently used to generate rates on the KPIs. Thus, it is within the control of each organisation to ensure data entry, and subsequent Dashboard output, is accurate and trustworthy. In our study, we identified sites with low engagement with the Dashboard, with data quality identified as a barrier to use by team members at these hospitals. Given that data quality is within the control of each hospital, it is possible that the absence of data quality improvement initiatives at these sites was related to team resistance to change or lack of knowledge and skill of how to actually improve data quality. Identifying and supporting hospitals that require assistance to train personnel and improve data entry processes may increase trust and utilisation of the Dashboard for quality improvement.

A review of 16 qualitative studies ${ }^{30}$ examining healthcare providers' experiences using feedback from patient reported outcome measures found several themes that resonate with our findings. Like our study where participants demonstrated knowledge gaps related to understanding the intricacies of the KPI rate calculations and how to interpret them, several studies included in the review identified important 'practical considerations' including appropriate training and statistical support to understand the data. In addition, the review highlighted the importance of healthcare providers understanding the rationale behind collecting and using the data, as well as the significance of practitioners' perceptions related to whether the data were a true reflection of clinical practice. In our study, sites in quadrant $1\left(\mathrm{P}^{+} / \mathrm{E}^{+}\right)$gave extensive examples of how Dashboard data are shared at multiple levels with multiple groups; this regular sharing and discussing of data likely facilitated the team's understanding and trust of the data.

Another feature of effective audit and feedback systems is that the recommended actions are within the control of the recipient. ${ }^{8}$ Our Dashboard audit and feedback system targets six KPIs, some of which are primarily physician practices and some of which are primarily nursing or laboratory technician practices. The use of multiple KPIs targeting multiple healthcare professionals made the change process more complex and challenging for sites without an existing culture of interprofessional collaboration. At several lower performing hospitals in quadrants $3(\mathrm{P} /$ $\left.\mathrm{E}^{+}\right)$and $4\left(\mathrm{P}^{-} / \mathrm{E}^{-}\right)$, we heard stories of interprofessional divides where nurses felt they did not have influence over physician driven KPIs. Yet overall, many nurses in our study spoke positively of the Dashboard and had 'going green' stories related to the nursing-driven KPIs. Similarly, a qualitative study ${ }^{31}$ explored the perceptions of nurses and nurse managers after implementation of unit-based dashboards. Overall, nurses responded positively to the dashboards and valued the ability to see the impact of their work on patient outcomes, the ability to track their progress over time and the ability to identify areas for improvement. In addition, a finding from a qualitative study ${ }^{32}$ exploring factors that influence success of audit and feedback in the intensive care unit setting was the importance of physician engagement-both in influencing physician practice change and in supporting nurses to implement change. This highlights the need to find strategies for professions to work collaboratively as many issues are complex and require work from the multidisciplinary team and management to achieve success. This resonates with the stories we heard in quadrant $1\left(\mathrm{P}^{+} /\right.$ $\left.\mathrm{E}^{+}\right)$, where increasing interprofessional communication and collaboration was a facilitator for success on KPIs. This is consistent with recommendations from the United Kingdom's Royal College of Obstetricians and Gynaecologists which state that the entire maternity team should be engaged in monitoring dashboard indicators. $^{33}$

\section{Implications}

The diversity in context within our case hospitals and in the facilitators and barriers they experienced demonstrates the challenges of implementing one audit and feedback system across an entire sector (all maternal-newborn hospitals). Assessing and addressing barriers is essential to optimise the effectiveness of audit and feedback interventions. ${ }^{8}$ A preimplementation hospital-level assessment to learn about the potential organisational barriers that may be encountered during implementation of a new dashboard or new KPI may facilitate identification 
of sites who need additional supports to fully use the dashboard for clinical practice change and inform development of tailored strategies to address local barriers to change. Furthermore, the use of a formal change process may facilitate implementation and monitoring of the targeted clinical practice change, particularly in high volume hospitals where the structure is larger and more complex. ${ }^{34}$

In our current study, we did not provide hospitals with action plans to guide the clinical practice change process, but several teams selected and implemented various formal change strategies and frameworks to facilitate practice change. Evidence from previous studies suggests that audit and feedback may be enhanced by the inclusion of specific action plans that provide guidance on how to improve performance. ${ }^{6}$ Other teams are exploring the effectiveness of audit and feedback augmented with additional supports such as educational outreach and implementation toolkits to assist with developing, implementing and monitoring a quality improvement plan. ${ }^{35} 36$ Cluster randomised controlled trials or quasi-experimental studies of augmented audit and feedback in maternal-newborn settings should be conducted to evaluate the effectiveness of co-interventions to optimise the effects of feedback.

\section{Strengths and limitations}

There are several important strengths of our study. We used a rigorous collective case study design to develop an in-depth understanding about how hospitals used the Dashboard and why some were successful and others were not. This study explored the use of a novel intervention to deliver audit and feedback nested within a large, province-wide birth registry in a healthcare system providing publicly-funded maternal-newborn care. Finally, we included representatives from different professional groups (eg, nursing, obstetrics, paediatrics, midwifery) as well as management, providing us with differing perspectives about barriers to use of data and practice change within 14 diverse hospital settings.

In this study, we visited 14 out of a potential 94 hospitals. Through the use of maximum variation sampling, diverse experiences were represented. Nevertheless, it is important to acknowledge that these findings are only transferable to similar contexts. In addition, while we classified the hospital sites into four quadrants to facilitate analysis of similarities and differences within and between groups, it is important to recognise that each organisation is comprised of individuals with different experiences and responses to the Dashboard. Another limitation is that several of our included sites had low birth volumes; the performance of these sites needs to be interpreted with caution since there was the possibility that colour changes on their Dashboard could simply be because small changes in either numerators or denominators could result in large changes in the KPI rates. The use of a qualitative case study design, however, allowed us to speak with team members at enrolled hospitals to help provide the context surrounding changes in performance on the KPIs, including the unique perspectives of these smaller sites.

\section{CONCLUSION}

The diversity of facilitators and barriers experienced across the 14 hospitals we visited highlights the need to go beyond a 'one size fits all' approach when implementing audit and feedback systems. There is a need to identify tools to assess likely barriers to practice change, to develop formal change processes and to evaluate the effects of cointerventions to optimise the effects of audit and feedback systems for clinical practice change in maternal-newborn care.

\section{Author affiliations}

'Better Outcomes Registry \& Network (BORN), Children's Hospital of Eastern Ontario - Ottawa Children's Treatment Centre (CHEO-OCTC), Ottawa, Ontario,

Canada

${ }^{2}$ Children's Hospital of Eastern Ontario Research Institute, Ottawa, Ontario,

Canada

${ }^{3}$ School of Nursing, University of Ottawa, Ottawa, Ontario, Canada

${ }^{4}$ Clinical Epidemiology Program, Ottawa Hospital Research Institute, Ottawa,

Ontario, Canada

${ }^{5}$ School of Epidemiology and Public Health, University of Ottawa, Ottawa,

Ontario, Canada

${ }^{6}$ Department of Medicine, University of Ottawa, Ottawa, Ontario, Canada

${ }^{7}$ McMaster Midwifery Research Centre, McMaster University, Hamilton, Ontario, Canada

${ }^{8}$ Division of Neonatology, Children's Hospital of Eastern Ontario and The Ottawa Hospital, Ottawa, Ontario, Canada

${ }^{9}$ Department of Pediatrics, University of Ottawa, Ottawa, Ontario, Canada ${ }^{10}$ Department of Obstetrics \& Gynecology, Queen's University and Kingston General Hospital, Kingston, Ontario, Canada

${ }^{11}$ Obstetrics, Maternal and Newborn Investigations (OMNI) Research Group,

Ottawa Hospital Research Institute, Ottawa, Ontario, Canada

${ }^{12}$ Department of Obstetrics, Gynecology and Newborn Care, The Ottawa Hospital, Ottawa, Ontario, Canada

${ }^{13}$ Department of Obstetrics and Gynecology, The University of Ottawa, Ottawa, Ontario, Canada

Contributors SID and MCW are coprincipal investigators for the described study. SID, AES, IDG, JMG, WEP, EKD, DBF, JH, GNS, MT, MCW contributed to the conceptualisation and the design of the study. JR, HO, JW, AQ visited the hospital sites and collected and coded all data. JR, HO, JW, AQ, SID, IDG, WEP, DW contributed to analysing the data. JR and SID drafted the initial manuscript. All authors participated in the writing of this manuscript and reviewed and approved the final manuscript.

Funding This study was funded by the Canadian Institutes of Health Research (CIHR-FRN: 133576) and the Ontario Ministry of Health and Long-Term Care (MOHLTC-\#06684). IDG is a recipient of a CIHR Foundation grant (FDN\# 143237). JMG is a recipient of a CIHR Foundation grant (FDN\# 143269). MCW is a recipient of a CIHR Foundation grant (FDN\# 148438).

Disclaimer The funding bodies had no role in study design, data collection, analysis, interpretation of data or the decision to submit this or future manuscripts for publication.

Competing interests None declared.

Patient consent for publication Not required. 
Ethics approval Children's Hospital of Eastern Ontario Research Ethics Board (\#13/218X) and University of Ottawa Research Ethics Board (\#A01-14-03).

Provenance and peer review Not commissioned; externally peer reviewed.

Data sharing statement The data analysed during this study (ie, interview and focus group transcripts, photographs and hospital documents) are not publicly available due to them containing information that could compromise research participant privacy/consent.

Open access This is an open access article distributed in accordance with the Creative Commons Attribution Non Commercial (CC BY-NC 4.0) license, which permits others to distribute, remix, adapt, build upon this work noncommercially, and license their derivative works on different terms, provided the original work is properly cited, appropriate credit is given, any changes made indicated, and the use is noncommercial. See: http://creativecommons.org/licenses/by-nc/4.0

\section{REFERENCES}

1 Pfuntner A, Wier L, Stocks C, 2013. Most Frequent Conditions in U.S. Hospitals, 2010: Statistical Brief \#148. Available: https://www.hcup-us.ahrq.gov/reports/statbriefs/sb148.pdf411 [Accessed 5 Dec 2018].

2 Canadian Institute for Health Information, 2017. Inpatient hospitalizations, surgeries, newborns and childbirth indicators, 2015-2016. Ottawa, Canada. Available: https://secure.cihi.ca/ free_products/cad_hospitalization_and_childbirth_snapshot_ 2015-2016_en.pdf [Accessed 5 Dec 2018].

3 Better Outcomes Registry \& Network (BORN) Ontario, 2016. 2014-2016 biennial report. Ottawa, Ontario. Available: https:// www.bornontario.ca/en/about-born/governance/annual-reports/ 2014-2016-annual-report/ [Accessed 5 Dec 2018].

4 Public Health Agency of Canada. Perinatal health indicators for Canada 2017. Ottawa ON, 2017.

5 Sprague AE, Dunn SI, Fell DB, et al. Measuring quality in maternal-newborn care: developing a clinical dashboard. $J$ Obstet Gynaecol Can 2013;35:29-38.

6 Ivers N, Jamtvedt G, Flottorp S, et al. Audit and feedback: effects on professional practice and healthcare Outcomes. Cochrane Database Syst Rev 2012;154.

7 Weiss D, Dunn SI, Sprague AE, et al. Effect of a populationlevel performance dashboard intervention on maternalnewborn outcomes: an interrupted time series study. BMJ Qual Saf 2018;27:425-36.

8 Brehaut JC, Colquhoun HL, Eva KW, et al. Practice feedback interventions: 15 suggestions for optimizing effectiveness. Ann Intern Med 2016;164:435-41.

9 Greenhalgh T. How to spread good ideas: A systematic review of the literature on diffusion, dissemination and sustainability of innovations in health service delivery and organisation. In: Report for the national co-ordinating centre for NHS service delivery and organisation R \& D (NCCSDO. London England, 2004.

10 Greenhalgh T, Robert G, Macfarlane F, et al. Diffusion of innovations in service organizations: systematic review and recommendations. Milbank Q 2004;82:581-629.

11 Estabrooks C. Translating research into practice: implications for organizations and administrators. Can J Nurs Res 2003;35:53-68.

12 Straus S, Tetroe J, Graham ID. Knowledge translation in health care: moving from evidence to practice. Oxford: WileyBlackwell, 2009.
13 Cane J, O'Connor D, Michie S. Validation of the theoretical domains framework for use in behaviour change and implementation research. Implementation Sci 2012;7.

14 Graham K, Logan J. Using the Ottawa model of research use to implement a skin care program. J Nurs Care Qual 2004;19:18-26.

15 Graham ID, Logan J, Harrison MB, et al. Lost in knowledge translation: time for a MAP? J Contin Educ Health Prof 2006;26:13-24.

16 Weiner BJ. A theory of organizational readiness for change. Implementation Sci 2009;4:1-9.

17 Vaughn VM, Saint S, Krein SL, et al. Characteristics of healthcare organisations struggling to improve quality: results from a systematic review of qualitative studies. BMJ Qual Saf 2019;28:74-84.

18 Dunn S, Sprague AE, Grimshaw JM, et al. A mixed methods evaluation of the maternal-newborn dashboard in Ontario: dashboard attributes, contextual factors, and facilitators and barriers to use: a study protocol. Implementation Sci $2015 ; 11$.

19 Stake RE. The art of case study research. Thousand Oaks, California: Sage Publications, 1995.

20 Sandelowski M. Whatever happened to qualitative description? Res Nurs Health 2000;23:334-40.

21 Sandelowski M. What's in a name? Qualitative description revisited. Res Nurs Health 2010;33:77-84.

22 Better Outcomes Registry \& Network (BORN) Ontario. Better Outcomes Registry \& Network (BORN) Ontario annual report 2012-2013 and 2013-2014. Ottawa Ontario, 2015.

23 Patton M. Qualitative Research \& Evaluation Methods. 4th edn. Thousand Oaks: Sage, 2015.

24 Morgan DL, Ataie J, Carder P, et al. Introducing dyadic interviews as a method for collecting qualitative data. Qual Health Res 2013;23:1276-84.

25 QSR International Pty Ltd. NVivo qualitative data analysis software, version 11, 2015.

26 Hsieh H-F, Shannon SE. Three approaches to qualitative content analysis. Qual Health Res 2005;15:1277-88.

27 Lincoln YS, Guba EG, Pilotta JJ. Naturalistic inquiry. Beverly Hills: Sage Publications, 1985: 9. 438-9.

28 van der Veer SN, de Keizer NF, Ravelli AC, et al. Improving quality of care. A systematic review on how medical registries provide information feedback to health care providers. Int J Med Inform 2010;79:305-23.

29 Dunn S, Sprague AE, Fell DB, et al. The use of a quality indicator to reduce elective repeat caesarean section for lowrisk women before 39 weeks' gestation: the eastern Ontario experience. J Obstet Gynaecol Can 2013;35:306-16.

30 Boyce MB, Browne JP, Greenhalgh J. The experiences of professionals with using information from patient-reported outcome measures to improve the quality of healthcare: a systematic review of qualitative research. BMJ Qual Saf 2014;23:508-18.

31 Jeffs L, Beswick S, Lo J, et al. Insights from staff nurses and managers on unit-specific nursing performance dashboards: a qualitative study. BMJ Qual Saf 2014;23:1001-6.

32 Sinuff T, Muscedere J, Rozmovits L, et al. A qualitative study of the variable effects of audit and feedback in the ICU. BMJ Qual Saf 2015;24:393-9.

33 Arulkumaran S, Chandraharan E, Mahmood T, et al. Maternity dashboard: clinical performance and governance score card. Good Pract 2007;7:1-7. 


\section{Original research}

34 NHS England Sustainable Improvement Team and the Horizons Team, 2018. Leading large scale change: a practical guide. quarry Hill. Available: https://www.england.nhs.uk/ wp-content/uploads/2017/09/practical-guide-large-scalechange-april-2018-smll.pdf [Accessed 5 Dec 2018].

35 van Engen-Verheul MM, Gude WT, van der Veer SN, et al. Improving guideline concordance in multidisciplinary teams: preliminary results of a cluster-randomized trial evaluating the effect of a web-based audit and feedback intervention with outreach visits. AMIA Annu Symp Proc 2015;2015:2101-10.
36 Hartley S, Foy R, Walwyn REA, et al. The evaluation of enhanced feedback interventions to reduce unnecessary blood transfusions (AFFINITIE): protocol for two linked cluster randomised factorial controlled trials. Implementation Sci 2017;12.

37 Provincial Council for Maternal and Child Health, 2013. Standardized maternal and newborn levels of care definitions. Available: http://www.pcmch.on.ca/wp-content/ uploads/2015/07/Level-of-Care-Guidelines-2011-UpdatedAugust1-20131.pdf [Accessed 5 Dec 2018]. 